\title{
Extramedullary Relapse of Acute Myeloid and Lymphoid Leukemia in Children: A Retrospective Analysis
}

\author{
Jee Young Kim, ${ }^{1}$ Soo Ah Im,,$^{1,}$ Ju Hyun Lee, ${ }^{1}$ Jae Wook Lee, ${ }^{2}$ Nak Gyun Chung, ${ }^{2}$ and Bin Cho ${ }^{2}$ \\ ${ }^{1}$ Department of Radiology, Seoul St. Mary's hospital, College of Medicine, The Catholic University of Korea, Seoul, Republic of Korea \\ ${ }^{2}$ Department of Pediatrics, Seoul St. Mary's hospital, College of Medicine, The Catholic University of Korea, Seoul, Republic of Korea \\ "Corresponding author: Soo Ah Im, Department of Radiology, Seoul St. Mary's hospital, College of Medicine, The Catholic University of Korea, Seoul, Republic of Korea. Tel: \\ +82-222581455, Fax: +82-25996771, E-mail: saim@catholic.ac.kr
}

Received 2015 April 10; Revised 2016 January 27; Accepted 2016 February 07.

\begin{abstract}
Background: Extramedullary relapse (EMR) is a recurrence of leukemia in sites other than the bone marrow, and it exhibits a relatively rare presentation of relapse of acute leukemia. However, EMR is an important cause of treatment failure among patients with acute leukemia. Therefore, early detection of these relapses may improve the prognosis.

Objectives: To describe the disease-related demographic and clinical features and radiologic findings for children diagnosed with EMR in acute leukemia.

Patients and Methods: The study was based on 22 children (M:F=14: 8; mean age 7.30 (2.1-15.7) years) with 8 acute myeloid leukemia (AML) and 14 acute lymphoid leukemia (ALL) who had experienced an EMR. Age, gender, clinical symptoms, initial extramedullary disease (EMD), French-American-British (FAB) morphology, cytogenetics, time to and site of EMR, concurrent bone marrow relapse (BMR), radiologic findings, and outcomes were evaluated.

Results: No definite relationship was found between initial EMD and EMR. A predilection for AML to relapse in the central nervous system (CNS), except for the CSF and bone, and for ALL to relapse in the CSF and kidney seemed to occur. Patients with EMR had a significantly higher incidence of $\mathrm{t}(8: 21)$ cytogenetics and FAB M2 and L1 morphologies. EMR accompanied with concurrent BMR occurred in $31.8 \%$ of the patients, who exhibited a relatively grave clinical course. Radiologic findings were nonspecific and had a great variety of structure involved, including bulging enhancing mass in the CT scan, hypoechoic mass in the US, and enhanced mass-like lesion in the MRI.

Conclusions: Knowledge of the potential sites of EMR, their risk factors, and their clinical and radiologic features may be helpful in the early diagnosis of relapse and planning for therapy.
\end{abstract}

Keywords: Leukemia, Relapse, Extramedullary Leukemia, Pediatrics

\section{Background}

Extramedullary relapse (EMR) is a recurrence of leukemia in sites other than the bone marrow, and it exhibits a relatively rare presentation of relapse of acute leukemia (1). However, the exact incidence of EMR remains unclear because the reported incidence has varied in previous studies. About 3\% - 5\% of patients are estimated to have an EMR in acute myeloid leukemia (AML) at some point in their lives (2-4). In acute lymphoid leukemia (ALL), approximately $20 \%$ will experience relapse. The cumulative risk of relapse is $11 \%$ in a 10 - year period, including EMR and bone marrow relapse (BMR) (5-7). EMR remains an important cause of treatment failure among patients with acute leukemia (3). The prognosis of EMR is poor with a median survival of only a few months $(3,4)$. Early detection of these relapses may improve the prognosis (1). The clinical characteristics and radiologic findings of EMR are limited because of its low incidence $(1,8)$. However,
EMR cases have been increasingly reported in the last few years (9).

\section{Objectives}

We aimed to describe the demographic and clinical features, radiologic findings, and clinical outcomes for children diagnosed with EMR in acute leukemia.

\section{Patients and Methods}

Our institutional review board approved this retrospective study and waived the requirement for an informed consent. We used our computerized hospital information system to identify all children under 16 years old who were diagnosed with EMR with acute leukemia presenting from January 1, 2009 to December 31, 2011 at our 
hospital. We respectively reviewed the clinical records and radiologic studies of these patients.

The diagnosis of EMR was established by tissue biopsy in six cases, examination of the CSF in seven cases, and clinical course and radiologic findings in residual cases. All patients who presented with EMR underwent a BM biopsy and aspiration for the evaluation of a possible coincident BMR within four (1 - 7) days after EMR diagnosis. Patients' past medical records were also reviewed for age, gender, white blood cell count (WBC), French-AmericanBritish (FAB) morphology, cytogenetics, and the presence of extramedullary disease (EMD) at initial diagnosis of acute leukemia. Time to and site of EMR, radiologic findings, and clinical course were also reviewed.

\section{Results}

\subsection{Patient Characteristics}

The number of EMR among acute leukemia patients was 22 ((M: $\mathrm{F}=14: 8$; mean age, 7.30 (2.1 - 15.7) years and initial diagnosis of acute leukemia, 1.7 - 15 years)). Among the patients, 14 had ALL and 8 patients had AML. Median WBC initially diagnosed as acute leukemia was $80.0 \times 10^{9} / \mathrm{L}$ (range $3-475.5 \times 10^{9} / \mathrm{L}$ ). Among the 22 patients, 14 had FAB L1 ALL, 5 had FAB M2 AML, and each of the 3 remaining had FAB Mo, M4, and M7, respectively. Cytogenetic results were available for 16 of the 22 patients. Leukemic cells of four patients had a normal karyotype, five had $\mathrm{t}(8: 21)$, two had $\mathrm{t}(9: 22)$, and one each had $\mathrm{t}(1: 18), \mathrm{t}(17: 19), \mathrm{t}(5: 10)$, $t(2: 12)$, and $t(1: 17)$, respectively. Only one of the patients had EMD at the first diagnosis (site of EMD: bilateral ocular/temporalis muscles, paranasal sinuses, skull base, nasal cavity, and both mastoid spaces).

EMR occurred with a median of 30.2 (4.4-117.5) months from the initial diagnosis of acute leukemia and 22.7 (2 116.5) months from complete remission (CR).

The disease-related features of the 22 patients with EMR are summarized in Table 1.

\subsection{Sites of EMR}

Table 2 summarizes the site distribution of the EMR. The site of EMR included the following: CSF $(n=7)$, brain $(n=2)$, brachial and sacral plexus $(n=2)$, bone $(n=6)$, kidney $(n=4)$, muscle $(n=2)$, liver $(n=2)$, lung $(n=1)$, pleura $(n=1)$, pancreas $(n=1)$, intestine $(n=1)$, peritoneum and omentum $(\mathrm{n}=1)$, parotid gland $(\mathrm{n}=1)$, lymph node $(\mathrm{n}=$ $2)$, breast $(n=1)$, ovary and uterus $(n=1)$, skin $(n=1)$, and testis $(n=2)$. The central nervous system $(\mathrm{CNS})$, bone, and kidney were the most common sites of EMR. Among the 22 patients, a single site of EMR was found in 13 patients and multiple sites in 9 patients. For the 5 patients with bone involvement, sites included the mastoid and temporal bone, sacrum, ulna, radius, and humerus. The sites of EMR were predominantly the CSF and kidney in ALL (29.2\% and 16.7\%, respectively) and the CNS except for CSF and bone in AML (28.6\% and $42.8 \%$, respectively).

\subsection{Clinical Characteristics Correlated With EMR}

Clinical symptoms included soft tissue or scrotal swelling $(n=5)$, pain $(n=6)$, fever $(n=4)$, headache with vomiting $(n=2)$, and no symptoms $(n=5)$. Among the seven patients with CSF relapse, five patients had no significant symptoms with the detection of CSF relapse during a routine follow-up. By contrast, for the patients with other EMR, all patients had symptoms, such as swelling, pain, and fever. Only one case of EMR with massive pancreatic involvement showed abnormality in blood chemistry that had led to it being mistaken for pancreatitis.

Among the 11 patients with symptoms of swelling and pain that involved the area, 4 patients (36.4\%) had additional relapsed sites without presenting symptoms.

At the time of EMR, examination of the BM aspirate did not show any evidence of leukemic recurrence in 10 (45.5\%) patients. Seven (31.8\%) patients had BMR at the time of EMR and five (22.7\%) patients had it 1 - 7.2 months (median, 3.4 months) later (Table 3 ).

\subsection{Radiologic Features of EMR}

Radiologic findings were nonspecific, and a variety of structures were involved. The EMR of CNS was hypointense or isointense on the T1-weighted magnetic resonance (MR) images and isointense or hyperintense on the T2-weighted MR images. The structures were enhanced homogenously after the injection of contrast media (Figures 1 and 2).

Bone and muscle lesions showed isointense and mildly hyperintense to normal muscle on T1- and T2- weighted MR images (Figure 3). Among the five cases of bone EMR involvement, four showed a permeative pattern of bone destruction with periosteal reaction on radiography. One case depicted MR images only. In the head and neck regions, EMR was presented with a bulging mass formation. Hepatic or renal involvement appeared as a well-defined solid mass, which could be indistinguishable from an abscess or lymphoma (Figure 4). Most EMR revealed discrete hypodense solid masses on the CT with a typically homogeneous enhancement (Figure 4). US helped with determining tumor extent and guiding biopsy. Echogenicity was generally homogenously hypoechoic with typical hypervascularity (Figure 5). 
Table 1. Disease-Related Features in Patients With Extramedullary Relapse of Acute Leukemia at the Initial Diagnosis of Acute Leukemia

\begin{tabular}{|c|c|c|c|c|c|c|c|}
\hline Case & Age & Sex & Type & FAB & $\mathrm{WBC}\left(\times 10^{9} / \mathrm{L}\right)$ & Cytogenetics & Extramedullary Disease \\
\hline $\mathbf{1}$ & 1.7 & M & $\mathrm{AM}$ & M7 & $\mathrm{N} / \mathrm{A}$ & $46, X Y$ & No \\
\hline 2 & 8 & $\mathrm{~F}$ & $\mathrm{~L}$ & M2 & 21.75 & $\mathrm{t}(8,21)$ & No \\
\hline 3 & 11 & M & $\mathrm{AM}$ & Mo & 65.80 & $t(5,10)$ & No \\
\hline 4 & 11 & $\mathrm{~F}$ & $\mathrm{~L}$ & M2 & 40.46 & $t(8,21)$ & No \\
\hline 5 & 15 & M & $\mathrm{AM}$ & M2 & 3.01 & $\mathrm{t}(8,21)$ & No \\
\hline 6 & 9 & M & L & M2 & 8.25 & $\mathrm{t}(8,21)$ & No \\
\hline 7 & 12 & M & $\mathrm{AM}$ & M4 & 23.28 & $46, X Y$ & No \\
\hline 8 & 2 & M & $\mathrm{L}$ & M2 & 24.06 & $t(8,21)$ & No \\
\hline 9 & 10 & $\mathrm{~F}$ & $\mathrm{AM}$ & L1 & 67.21 & $\mathrm{t}(17,19)$ & Yes $^{\mathrm{a}}$ \\
\hline 10 & 4 & M & $\mathrm{L}$ & L1 & 5.0 & $\mathrm{~N} / \mathrm{A}$ & No \\
\hline 11 & 2.1 & $\mathrm{~F}$ & $\mathrm{AM}$ & L1 & 47.99 & $\mathrm{t}(2,12)$ & No \\
\hline 12 & 12 & M & $\mathrm{L}$ & L1 & $\mathrm{N} / \mathrm{A}$ & $\mathrm{N} / \mathrm{A}$ & No \\
\hline 13 & 13 & $\mathrm{M}$ & AM & L1 & $\mathrm{N} / \mathrm{A}$ & $\mathrm{N} / \mathrm{A}$ & No \\
\hline 14 & 6 & M & $\mathrm{L}$ & L1 & 11.66 & $\mathrm{t}(1,18)$ & No \\
\hline 15 & 2 & $\mathrm{~F}$ & $\mathrm{AM}$ & L1 & $\mathrm{N} / \mathrm{A}$ & $\mathrm{N} / \mathrm{A}$ & No \\
\hline 16 & 7 & F & $\mathrm{L}$ & L1 & 475.52 & $\mathrm{t}(9,22)$ & No \\
\hline 17 & 6 & M & ALL & L1 & 88.35 & $\mathrm{t}(9,22)$ & No \\
\hline 18 & 15 & M & ALL & L1 & 66.0 & $46, X Y$ & No \\
\hline 19 & 4 & F & ALL & L1 & 7.4 & $\mathrm{~N} / \mathrm{A}$ & No \\
\hline 20 & 7 & $\mathrm{~F}$ & ALL & L1 & 290.82 & $\mathrm{t}(1,17)$ & No \\
\hline 21 & 3 & M & ALL & L1 & 69.85 & $46, X Y$ & No \\
\hline 22 & 3 & M & ALL & L1 & $\mathrm{N} / \mathrm{A}$ & $\mathrm{N} / \mathrm{A}$ & No \\
\hline
\end{tabular}

Abbreviation: N/A, not available.

a bilateral ocular/temporalis muscles, paranasal sinuses, skull base, nasal cavity, and both mastoid spaces

\subsection{Clinical Course of EMR}

The treatment and outcome of the patients with EMR are listed in Table 3. Seven EMR patients with concurrent BMR showed a relatively grave clinical course, and three of the seven expired. Among the 22 patients with EMR, 5 patients expired with a median of 15.1 (2.2 - 39) weeks. The CR from the EMR occurred with a median of 10.3 (2 -20) weeks. The CR from the BMR occurred with a median of $10.3(2-20)$ weeks.

\section{Discussion}

Although the prognostic significance and management of EMR in acute leukemia is controversial because of its low incidence, EMR reports have demonstrated several meaningful results (3-5, 9-12).

Factors predisposing EMR to AML include an abnormal karyotype (e.g., $\mathrm{t}(8 ; 21)$, inv(16) and t(11q23)) FAB type M4, five morphologies, and strong male predominance $(3,11)$. Additional EMR risk factors for ALL include male sex, age < 1 year or 10 years at diagnosis, WBC count of $>50,000 / \mathrm{L}$, T-cell lineage, and cytogenic abnormalities such as $\mathrm{t}(9 ; 22)$ $(4,5,12)$. In our study, patients with EMR had a significantly higher incidence of $\mathrm{t}(8 ; 21)$ cytogenetics. The most frequent FAB morphology was M2 in AML and L1 in ALL patients. A strong male predominance (68.2\%) was also found.

Patients with or without prior EMD had different EMR rates (11). However, unlike previous studies, we found no significant correlation between initial EMD at first diagnosis and EMR. In our series, only 1 patient out of $22 \mathrm{~s}$ with EMR had initial EMD. However, the possibility of initial EMD cannot be completely excluded because the entire body screening is not usually performed at the initial work-up for acute leukemia except for symptomatic lesions.

EMR may occur at any part of the body. The most common sites of EMR are the CNS and skin in AML and CNS and 

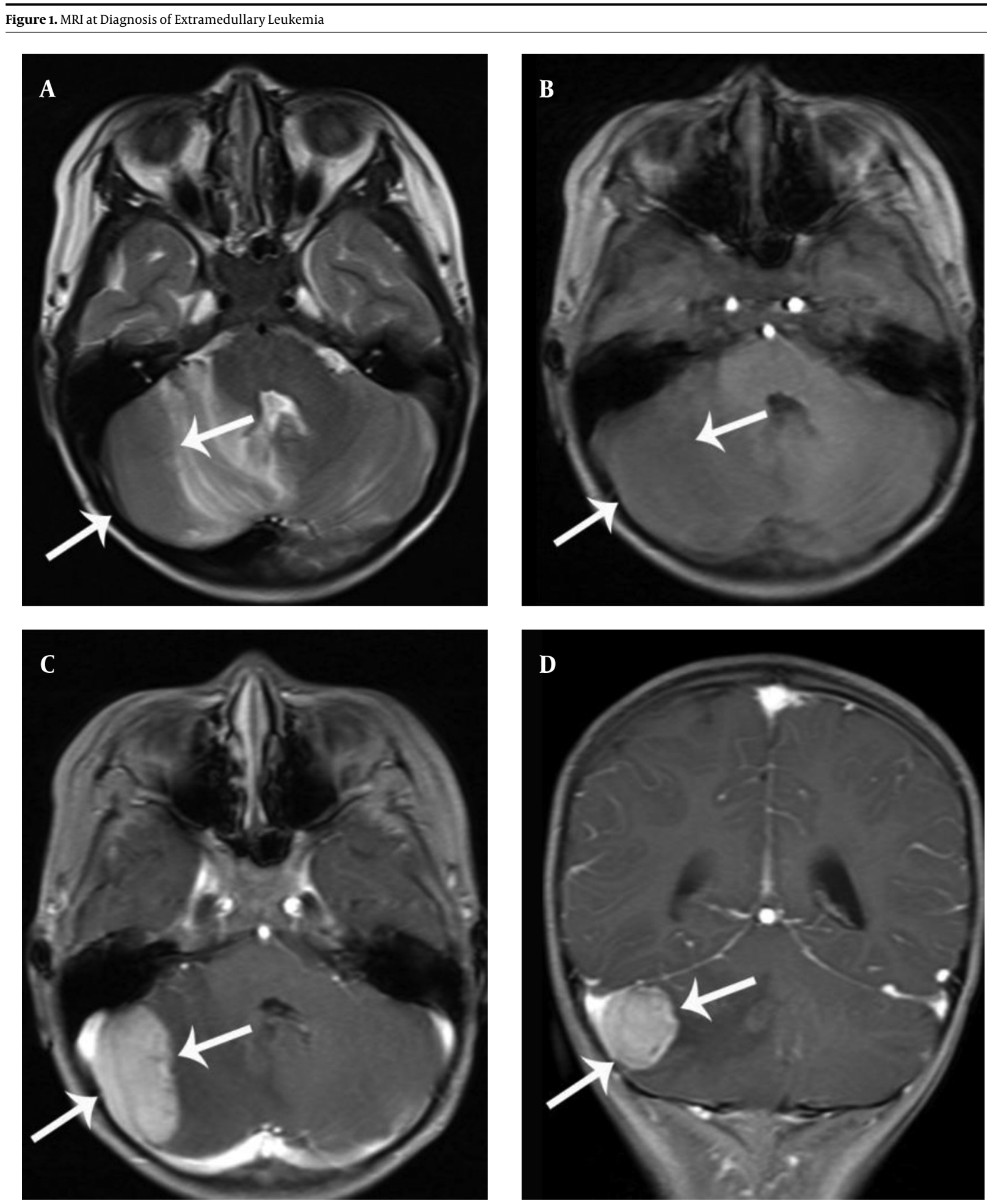

A, Axial T2 and B, axial T1 showing a round mass in the periphery of the right cerebellum with surrounding edema (arrows). C, Axial T1 and D, coronal T1 with gadolinium reveal a homogenous enhancement of lesion (arrows). 
Table 2. Sites of Extramedullary Relapse in Acute Leukemia

\begin{tabular}{|lccc}
\hline Sites of Extramedullary Relapse & AML & ALL & Total \\
\hline Central nervous system & 4 & 7 & 11 \\
\hline \multicolumn{1}{|c}{ Brain } & 2 & 0 & 2 \\
\hline \multicolumn{1}{|c}{ Brachial and sacral plexus } & 2 & 0 & 2 \\
\hline Bone & 0 & 7 & 7 \\
\hline Kidney & 6 & 0 & 6 \\
\hline Muscle & 0 & 4 & 4 \\
\hline Liver & 2 & 0 & 2 \\
\hline Lung & 0 & 2 & 2 \\
\hline Pleura & 1 & 0 & 1 \\
\hline Pancreas & 1 & 0 & 1 \\
\hline Intestine & 0 & 1 & 1 \\
\hline Peritoneum and omentum & 0 & 1 & 1 \\
\hline Parotid gland & 0 & 1 & 1 \\
\hline Lymph node & 0 & 1 & 1 \\
\hline Breast & 0 & 1 & 1 \\
\hline Ovary and uterus & 0 & 2 & 2 \\
\hline Testis & 0 & 1 & 1 \\
\hline Skin & 0 & 38 \\
\hline Total & 0 & 24 \\
\hline
\end{tabular}

Figure 2. MRI at Diagnosis of Extramedullary Leukemia

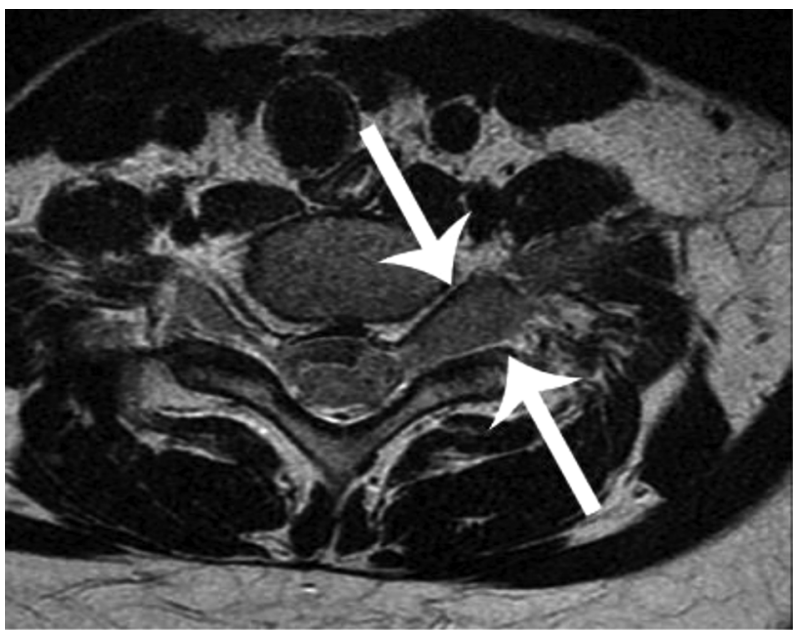

Axial T1 showing a fusiform enlargement of the left brachial plexus (arrows). testis in ALL $(4,9,10)$. The most frequent site of EMR in our patients was the CNS, but different results were found in the predominant sites of EMR patients with AML and ALL. The sites of EMR were predominantly CNS except for CSF and bone in AML $29.2 \%$ and $16.7 \%$, respectively) and CSF and kidney in ALL (28.6\% and $42.8 \%$, respectively).

EMR may herald BMR (within 1 to 12 months), and thus a prompt EMR diagnosis is necessary $(5,13)$. Our series revealed a similar finding and the mean interval until BMR was $3.4(1-7.2)$ months.

The prognosis was better known among patients with isolated EMR than among patients with concurrent BMR or later $(14,15)$. In our series, EMR patients had concurrent BMR in $31.8 \%$ and exhibited a relatively grave clinical course.

A low incidence of EMR may cause misdiagnosis and delay in therapy. In addition, the radiologic features of EMR are usually similar to those of lymphoma, infection, and secondary neoplasm $(1,16,17)$. However, EMR should be considered whenever a mass is newly detected in a patient with a history of acute leukemia.

Our study has several limitations. First, this work was a retrospective study and was based on a small number of patients. Second, we did not have pathologic confirmation of EMR in every case.

\subsection{Conclusion}

In conclusion, EMR appears to have a predilection for AML in CNS except for CSF and bone and ALL in CSF and kidney. No definite relationship was found between the initial EMD and EMR. Patients with EMR had a significantly high incidence of $\mathrm{t}(8: 21)$ cytogenetics and FAB M2 and L1 morphologies. Knowledge of the potential sites of EMR and their risk factors may be helpful in the early diagnosis of relapse and planning for therapy. Additional studies with greater samples may be needed to define the risk factors and prognostic indicators. 
Table 3. Treatment and Outcome of the Patients With Extramedullary Relapse

\begin{tabular}{|c|c|c|c|c|c|c|c|}
\hline Case & Type & EMR Sites & Treatment & BMR & Treatment Response & CR of BMR & CR of EMR \\
\hline $\mathbf{1}$ & AML & Bone, brain & CTx & Yes & Expire & - & - \\
\hline 2 & AML & Pleura, bone, muscle & CTx & Yes & Expire & - & - \\
\hline 3 & AML & Brachial plexus & CTx & No & $\mathrm{CR}$ & - & 56 weeks \\
\hline 4 & AML & Bone, sacral plexus & CTx & No & $\mathrm{CR}$ & - & 4 weeks \\
\hline 6 & AML & Brain & CTx & Yes & FU loss & - & - \\
\hline 7 & AML & Lung, bone & CTx & Yes & Expire & - & - \\
\hline 8 & AML & Bone & CTx & No & $\mathrm{CR}$ & - & 6.3 weeks \\
\hline 9 & ALL & Skin, LN, ovary, uterus, breast, liver, kidney & CTx & 23 weeks & $\mathrm{CR}$ & 4 weeks & 5.4 weeks \\
\hline 10 & ALL & Testis & CTx, RTx & No & $\mathrm{CR}$ & - & 10.2 weeks \\
\hline 12 & ALL & Testis & CTx & No & Expire & - & - \\
\hline 13 & ALL & Kidney & CTx & 4 weeks & Expire & - & - \\
\hline 14 & ALL & Pancreas, kidney, peritoneum, omentum & CTx & 24 weeks & FU loss & - & - \\
\hline 16 & ALL & Intestine & CTx & No & $\mathrm{CR}$ & - & 4.2 weeks \\
\hline 17 & ALL & CSF & CTx & No & $\mathrm{CR}$ & - & 3 weeks \\
\hline 17 & ALL & CSF & CTx & Yes & $\mathrm{CR}$ & 16 weeks & 4.2 weeks \\
\hline 18 & ALL & CSF & CTx & No & $\mathrm{CR}$ & - & 11.6 weeks \\
\hline 19 & ALL & CSF & CTx & 20 weeks & $\mathrm{CR}$ & 20 weeks & 42 weeks \\
\hline 20 & ALL & CSF & CTx & No & $\mathrm{CR}$ & - & 5.4 weeks \\
\hline 21 & ALL & CSF & CTx & Yes & $\mathrm{CR}$ & 6.3 weeks & 6.5 weeks \\
\hline
\end{tabular}


Figure 3. MRI at Diagnosis of Extramedullary Leukemia
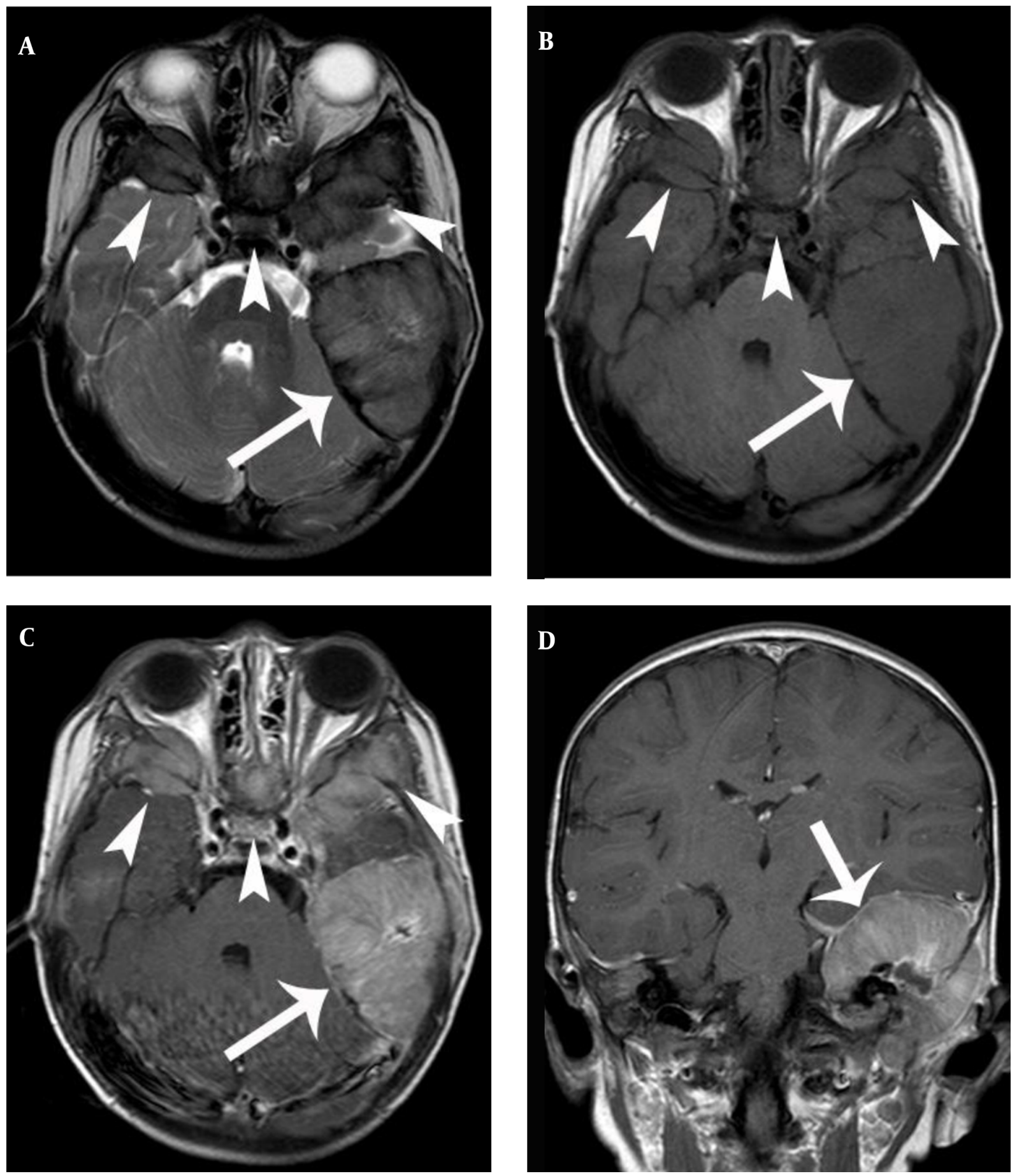

A, Axial T2 and B, axial T1 showing a large bulging mass on the left mastoid (arrow) and similar lesions involving the skull base and orbits (arrowheads). C, Axial T1 and D, coronal T1 with gadolinium reveal a relatively homogenous enhancement with a central non-enhancing area (arrow, arrowheads). 
Figure 4. CT at Diagnosis of Extramedullary Leukemia
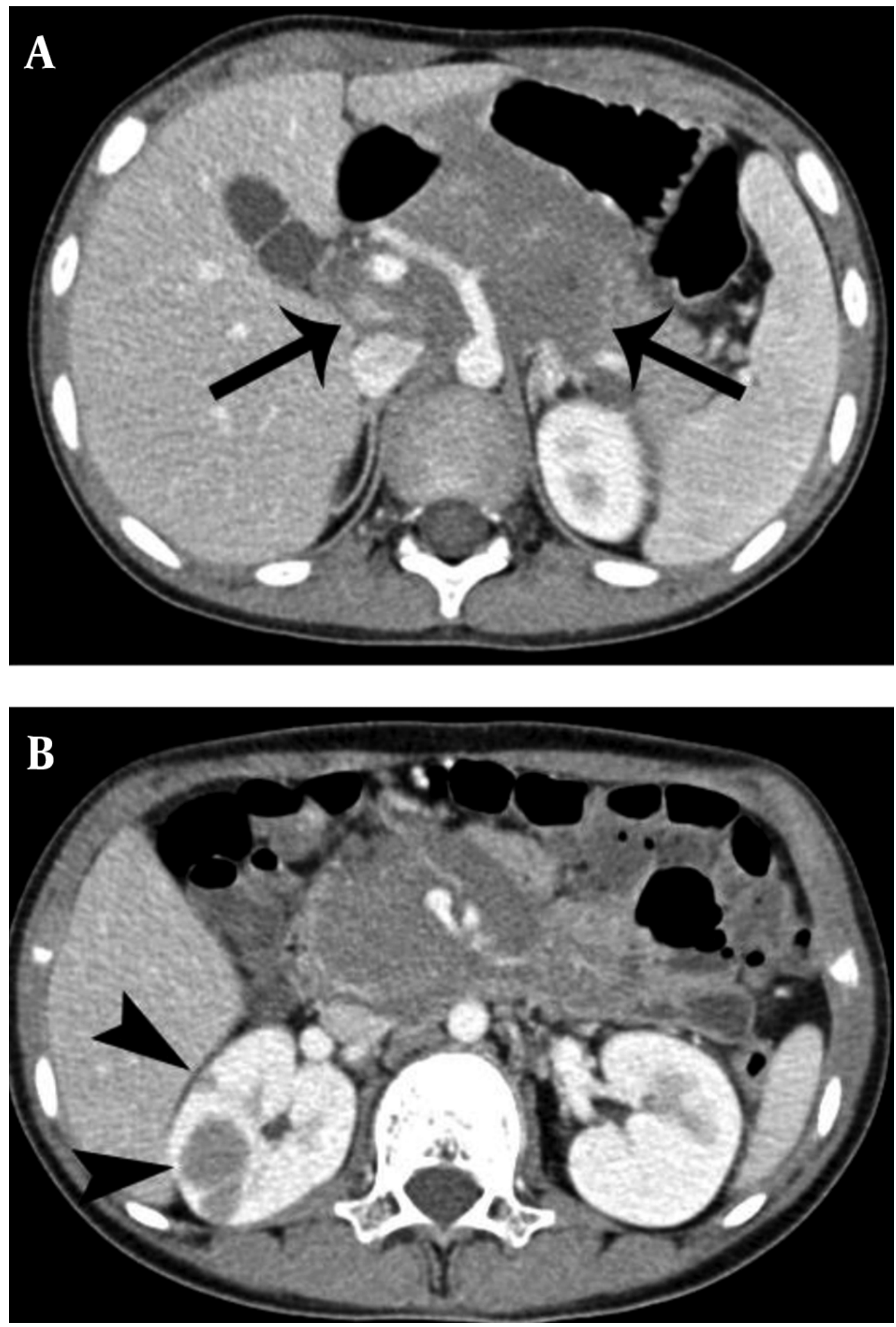

Enhanced CT showing a hypodense mass of mesentery root and the pancreas head (arrows) (A), and hypodense oval lesions on the right kidney (arrowheads) (B). Abdominal pain occurred with increased serum amylase and lipase level in this patient. 
Figure 5. US at Diagnosis of Extramedullary Leukemia
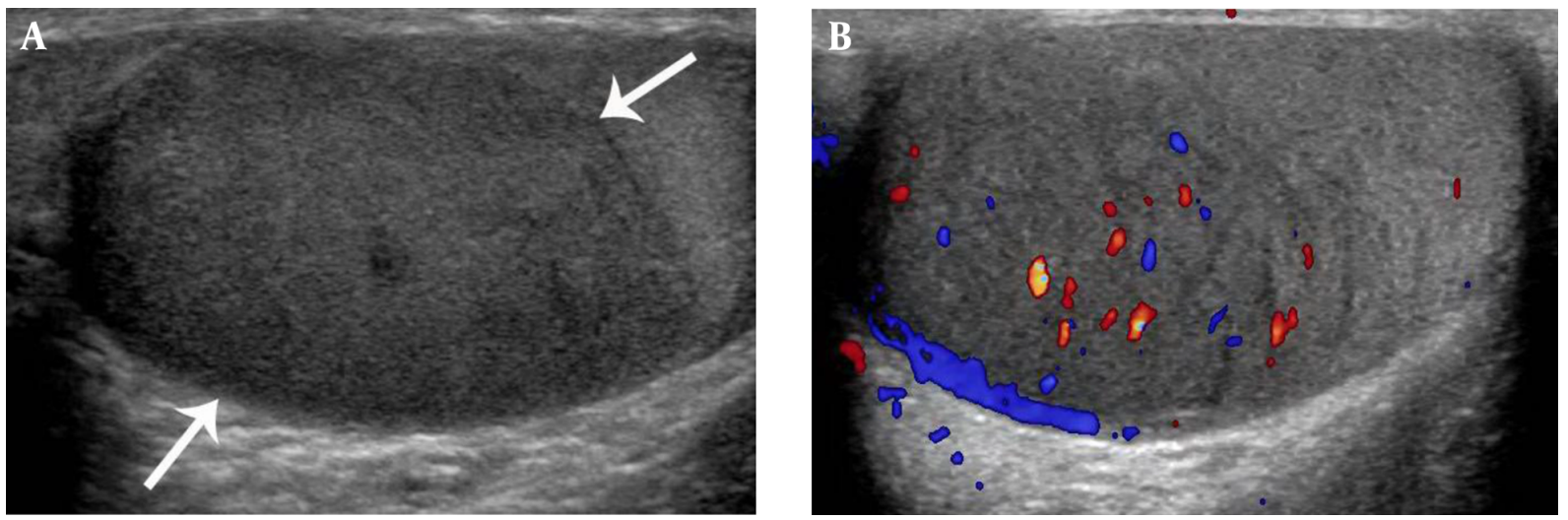

Longitudinal scan through the scrotum showing an ill-defined hypoechoic mass posteriorly (arrows) (A) and Doppler sonography showing hypervascular flow signals (B). 


\section{Footnotes}

Authors' Contribution: Concept and design, Soo Ah Im, Jee Young Kim, and Ju Hyun Lee; acquisition of data, Jee Young Kim and Ju Hyun Lee; data analysis/interpretation, Soo Ah Im, Jee Young Kim, and Ju Hyun Lee; drafting of manuscript, Jee Young Kim and Ju Hyun Lee; critical revision of the manuscript and approval of article, Soo Ah Im, Jee Young Kim, Ju Hyun Lee, Jae Wook Lee, Nak Gyun Chung, and Bin Cho.

Financial Disclosure: The authors declare that they have no conflict of interest.

\section{References}

1. Fritz J, Vogel W, Bares R, Horger M. Radiologic spectrum of extramedullary relapse of myelogenous leukemia in adults. AJR Am J Roentgenol. 2007;189(1):209-18. doi: 10.2214/AJR.06.1500. [PubMed: 17579173].

2. Yoshihara S, Ikegame K, Kaida K, Taniguchi K, Kato R, Inoue T, et al. Incidence of extramedullary relapse after haploidentical SCT for advanced AML/myelodysplastic syndrome. Bone Marrow Transplant. 2012;47(5):669-76. doi: 10.1038/bmt.2011.163. [PubMed: 21860427].

3. Clark WB, Strickland SA, Barrett AJ, Savani BN. Extramedullary relapses after allogeneic stem cell transplantation for acute myeloid leukemia and myelodysplastic syndrome. Haematologica. 2010;95(6):860-3. doi: 10.3324/haematol.2010.025890. [PubMed: 20513805].

4. Vega-Ruiz A, Faderl S, Estrov Z, Pierce S, Cortes J, Kantarjian H, et al. Incidence of extramedullary disease in patients with acute promyelocytic leukemia: a single-institution experience. Int J Hematol. 2009;89(4):489-96. doi: 10.1007/s12185-009-0291-8. [PubMed: 19340529].

5. Freyer DR, Devidas M, La M, Carroll WL, Gaynon PS, Hunger SP, et al. Postrelapse survival in childhood acute lymphoblastic leukemia is independent of initial treatment intensity: a report from the Children's Oncology Group. Blood. 2011;117(11):3010-5. doi:10.1182/blood-2010-07294678. [PubMed: 21193696].

6. Roy A, Cargill A, Love S, Moorman AV, Stoneham S, Lim A, et al. Outcome after first relapse in childhood acute lymphoblastic leukaemia - lessons from the United Kingdom R2 trial. Br J Haematol. 2005;130(1):67-75. doi: 10.1111/j.1365-2141.2005.05572.x. [PubMed: 15982346].
7. Pui CH, Pei D, Sandlund JT, Campana D, Ribeiro RC, Razzouk BI, et al. Risk of adverse events after completion of therapy for childhood acute lymphoblastic leukemia. J Clin Oncol. 2005;23(31):7936-41. doi 10.1200/JCO.2004.01.0033. [PubMed: 16258093].

8. Ginsberg JP, Orudjev E, Bunin N, Felix CA, Lange BJ. Isolated extramedullary relapse in acute myeloid leukemia: A retrospective analysis. Med Pediatr Oncol. 2002;38(6):387-90. doi: 10.1002/mpo.10069. [PubMed: 11984798].

9. de Botton S, Sanz MA, Chevret S, Dombret H, Martin G, Thomas $\mathrm{X}$, et al. Extramedullary relapse in acute promyelocytic leukemia treated with all-trans retinoic acid and chemotherapy. Leukemia. 2006;20(1):35-41. doi: 10.1038/sj.leu.2404006. [PubMed: 16307026].

10. Cunningham I. Extramedullary sites of leukemia relapse after transplant. Leuk Lymphoma. 2006;47(9):1754-67. doi: 10.1080/10428190600632857. [PubMed: 17064985].

11. Dinsmore R, Kirkpatrick D, Flomenberg N, Gulati S, Kapoor N, Shank B, et al. Allogeneic bone marrow transplantation for patients with acute lymphoblastic leukemia. Blood. 1983;62(2):381-8. [PubMed: 6347274].

12. Nguyen $K$, Devidas $M$, Cheng SC, La M, Raetz EA, Carroll WL, et al. Factors influencing survival after relapse from acute lymphoblastic leukemia: a Children's Oncology Group study. Leukemia. 2008;22(12):2142-50. doi: 10.1038/leu.2008.251. [PubMed: 18818707].

13. Park J, Park SY, Cho HI, Lee D. Isolated extramedullary relapse in the pleural fluid of a patient with acute myeloid leukemia following allogeneic BMT. Bone Marrow Transplant. 2002;30(1):57-9. doi: 10.1038/sj.bmt.1703572. [PubMed: 12105780].

14. Harris AC, Kitko CL, Couriel DR, Braun TM, Choi SW, Magenau J, et al. Extramedullary relapse of acute myeloid leukemia following allogeneic hematopoietic stem cell transplantation: incidence, risk factors and outcomes. Haematologica. 2013;98(2):179-84. doi: 10.3324/haematol.2012.073189. [PubMed: 23065502].

15. Mo XD, Kong J, Zhao T, Xu LP, Zhang XH, Liu DH, et al. Extramedullary relapse of acute leukemia after haploidentical hematopoietic stem cell transplantation: incidence, risk factors, treatment, and clinical outcomes. Biol Blood Marrow Transplant. 2014;20(12):2023-8. doi: 10.1016/j.bbmt.2014.08.023. [PubMed: 25196855].

16. Guermazi A, Feger C, Rousselot P, Merad M, Benchaib N, Bourrier $P$, et al. Granulocytic sarcoma (chloroma): imaging findings in adults and children. AJR Am J Roentgenol. 2002;178(2):319-25. doi: 10.2214/ajr.178.2.1780319. [PubMed: 11804886].

17. Ooi GC, Chim CS, Khong PL, Au WY, Lie AK, Tsang KW, et al. Radiologic manifestations of granulocytic sarcoma in adult leukemia. AJR Am J Roentgenol. 2001;176(6):1427-31. doi: 10.2214/ajr.176.6.1761427. [PubMed: 11373207]. 